\title{
The toxicity of Lake Onego sediments in connection with the natural and anthropogenic factors influence
}

\author{
N.M. Kalinkina ${ }^{1}$, A.I. Sidorova ${ }^{1}$, N.A. Galibina ${ }^{2}$, K.M. Nikerova ${ }^{2}$ \\ ${ }^{1}$ Northern Water Problems Institute, Karelian Research Center, Russian Academy of \\ Sciences 50 A. Nevsky ave., Petrozavodsk, 185030, Russia \\ E-mail:cerioda@mail.ru \\ ${ }^{2}$ The Forest Institute, Karelian Research Center, Russian Academy of Sciences \\ 11 Pushkinskaya str., 185910, Petrozavodsk, Russia
}

\begin{abstract}
The toxicity of the sediments detected in the northern bays of Lake Onego is determined by anthropogenic factors (pulp-and-paper industry and communal waste waters). Besides the toxic bottom sediments were observed in the central deep part of Lake Onego, which is connected to the geotectonic features of the area.
\end{abstract}

Keywords: lake Onego, bottom sediments, bioassay, anthropogenic influence.

\section{INTRODUCTION}

Lake Onego (the northwestern part of Russia, Karelia) is one of the largest freshwater reservoirs with a great storage of high quality water $-295 \mathrm{~km}^{3}$ [1]. Lake Onego provides a strategic reserve of drinking water and requires special principles and methods of monitoring and protection.

At present time, the ecosystem of Lake Onego for most of its water area (in central deep parts) retains natural status, which is characterized as oligotrophic. Nevertheless, the northern bays of this lake now undergoing major changes associated with eutrophication. The main sources of pollution of the lake are situated on the banks of the northern bays. They are associated with the industrial towns Petrozavodsk, Kondopoga, and Medvezhyegorsk (Fig. 1).

Also, Lake Onego is influenced by trout farms which tend to grow nowadays. Now in Karelia annual production of trout is about 12,000 tons $(70 \%$ of the total amount in Russia), of which 5300 tons are produced in Lake Onego [2]. Thus, the regular monitoring of Lake Onego is required.

According to the modern principles of biomonitoring, hydrobiological indicators are of high priority for assessment of aquatic ecosystems [3; 4]. Bioassay of water and sediment is one of the main elements of biomonitoring. Methods of sediments bioassay have been developed relatively recently [5; 6]. Their approbation is necessary for the conditions of Lake Onego.
The purpose of the report is to present the results of bioassay of bottom sediments of Lake Onego and to consider the reasons for their toxicity..

\section{MATERIALS AND METHODS}

The field campaign on Lake Onego was carried out on the research vessel "Ecolog" in August, 2014. Samples of sediment were collected at 47 stations with depths of 4.5-104 m (Fig. 1). The upper surface (3 cm) layer of silts was selected for bioassay. According to methodology [7], aqueous extract was obtained from samples of sediment and then was tested.

Planktonic crustacean Ceriodaphnia affinis Lillijeborg was used as a test-organism. The biotest with using of Ceriodaphnia affinis (Cladocera) was adapted for the purposes of environmental monitoring about 15 years ago [8]. The species Ceriodaphnia affinis is the best test for express evaluation of the aqueous extract sediment toxicity [6;9]. This species was used to evaluate the bottom toxicity of the large water bodies of the northwestern part of Russia [10].

The duration of the bioassay experiments was 5 days. All experiments were carried out at a water temperature of $19.5-21^{\circ} \mathrm{C}$. The experiments were in duplicate. Five examples of crustaceans were placed in each vessel. Two kinds of water were used as a control: ground water $(\mathrm{pH}=8.02)$, used for the cultivation of crustacean Ceriodaphnia affinis, and water from the central area of Lake Onego $(\mathrm{pH}=$ 7.54), used for the preparation of extracts from sediments. The survival of the crustaceans in the 
control was $100 \%$. In total 1050 examples of crustaceans were used in the experiments, including 110 examples in the control experiments.

In sediments the total sulfur content was determined by spectrophotometric method [11]. The amount of sodium lignosulfonates in sediment samples was determined by spectrophotometric method by reacting with nitric acid [12]. Organic carbon content was determined by method of Turin [13]. The amount of total nitrogen content and total phosphorus was determined by spectrophotometric method [14]. The amount of all components was calculated in percent of dry weight of sediment.

\section{RESULTS AND DISCUSSION}

According to results of bioassay of aqueous extracts two different toxicity groups of sediments were determined. The majority of sediment samples (29 of 47, i.e. 61\%) were non-toxic. On the Figure 1 the stations with non-toxic sediments are shown by dots.

The distribution of stations with different toxic sediments is presented in Fig. 1 (these stations are shown by stars). The most toxicity sediment were found in the different part of Lake Onego (Table 1). Six samples of toxic sediments (stations 6, 7, 8, 9, 10, 11) were found in the northern polluted bays. Three stations with toxic sediments $(7,8,9)$ were situated in Kondopozhskaya Bay, where the main source of pollution of Lake Onego (Kondopozhskiy pulp-andpaper mill) is situated. The reasons of toxicity of sediments in the Kondopozhskaya Bay are associated with the large concentration of sodium lignosulfonate (the main component of pulp-and-paper mill wastewaters). Its content in sediments (\% of dry weight) ranged 0,030-0,059. In the other samples of sediments sodium lignosulfonate was not found. Besides high concentrations of total sulfur, organic matter (organic carbon), nitrogen, phosphorus were found in the sediments of Kondopozhskaya Bay (Table 2). All these figures reflect the impact of pulpand-paper mill, which has discharged their sewage into the Kondopozhskaya Bay for more than 80 years.

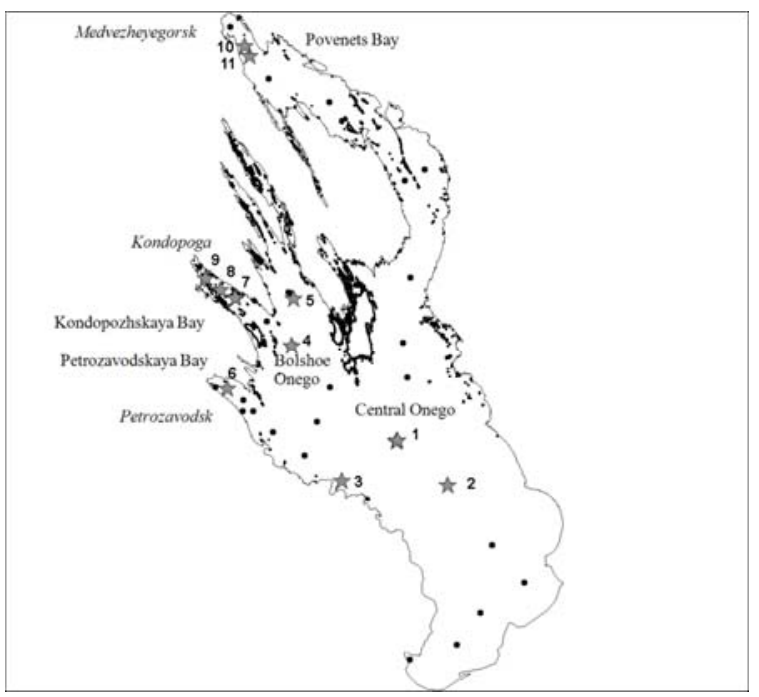

Fig. 1. The Lake Onego. Stars - toxicity of bottom sediments (survival-rate $0-30 \%$ ); dots - not toxicity of bottom sediments (survival-rate 80-100\%).

TABLE I

The survival rate of Ceriodaphnia affinis in the aqueous extract of the most toxic bottom sediments in Lake Onego

Note: * Number of station - see Fig. 1.

\begin{tabular}{|c|c|c|}
\hline Part of Lake & $\begin{array}{l}\text { Number of } \\
\text { station* }\end{array}$ & Limits of survival-rate, $\%$ \\
\hline Kondopozhskaya Bay & $7,8,9$ & $0-20$ \\
\hline Petrozavodskaya Bay & 6 & 0 \\
\hline Povenets Bay & 10,11 & $0-60$ \\
\hline Bolshoe Onego & 4,5 & $0-40$ \\
\hline Central Onego & $1,2,3$ & $0-40$ \\
\hline
\end{tabular}

TABLE II

Parameteres of the chemical composition of sediments of Lake Onego, \% of dry weight

\begin{tabular}{|c|c|c|c|c|c|}
\hline Part of Lake & $\begin{array}{c}\text { Statistical } \\
\text { parameteres }\end{array}$ & organic carbon & total sulfur & total phosphorus & total nitrogen \\
\hline \multirow[t]{3}{*}{ Kondopozhskaya Bay } & Average & 4,85 & 0,31 & 0,24 & 0,49 \\
\hline & Min & 1,59 & 0,15 & 0,17 & 0,29 \\
\hline & $\max$ & 14,66 & 0,58 & 0,35 & 1,06 \\
\hline \multirow[t]{3}{*}{ Petrozavodskaya Bay } & Average & 1,67 & 0,14 & 0,15 & 0,23 \\
\hline & Min & 0,54 & 0,08 & 0,06 & 0,17 \\
\hline & $\max$ & 2,68 & 0,17 & 0,22 & 0,28 \\
\hline \multirow[t]{3}{*}{ Povenets Bay } & Average & 4,01 & 0,12 & 0,16 & 0,20 \\
\hline & Min & 0,31 & 0,10 & 0,11 & 0,18 \\
\hline & $\max$ & 7,35 & 0,13 & 0,20 & 0,24 \\
\hline \multirow[t]{3}{*}{ Bolshoe Onego } & Average & 1,92 & 0,15 & 0,26 & 0,30 \\
\hline & Min & 0,91 & 0,11 & 0,13 & 0,10 \\
\hline & $\max$ & 4,07 & 0,18 & 0,43 & 0,46 \\
\hline \multirow[t]{3}{*}{ Central Onego } & Average & 3,88 & 0,16 & 0,19 & 0,28 \\
\hline & Min & 2,31 & 0,13 & 0,14 & 0,20 \\
\hline & $\max$ & 5,50 & 0,18 & 0,25 & 0,35 \\
\hline
\end{tabular}


Increased concentration of sulfur in the sediments of the Kondopozhskaya Bay is associated with the sewage of a pulp-and-paper mill. The sulfur compounds, which are used in the wood pulping process reacts with lignin substances and form sodium lignosulfonate, which is deposited and accumulated in the sediments. It leads to an increase of the sulfur content in sediments. It can be assumed that the toxicity of sediments is connected with the pollutants that have been accumulated in sediments of Kondopozhskaya Bay.

Toxic samples of sediments were also observed in the Petrozavodskaya bay. This station (number 6) is deep (depth of $26.7 \mathrm{~m}$ ) and is located opposite the harbor of Petrozavodsk. The area accumulates pollutants coming from the territory of the city of Petrozavodsk which determines the toxicity of the sediments. Toxic sediments were also found in the upper part of the Povenets Bay (stations 10,11) that reflects the impact of wastewaters from the city of Medvezhyegorsk.

The toxic sediments from the central deep parts of Lake Onego (Bolshoe Onego and Central Onego, stations 1, 2, 3, 4, 5) are of the greatest interest (Fig. 1 ). These are the most deep areas (depth of 40-100 m). The reason of toxicity of the sediments from these areas comes from the increased concentrations of trace elements, which enter the sediment as a result of subaqueous discharge. Lake Onego, like other deep lakes of Karelia, located in the zone of tectonic faults [15]. According the data [16] in deep-water areas of Lake Onego (Bolshoe Onego) anomalous distribution of chemical parameters $\left(\mathrm{CO}_{2}\right.$, trace elements, $\left.\mathrm{pH}\right)$ and conductivity were found in the upper bottom layer. The conductivity reached up to $140 \mathrm{mkS} / \mathrm{cm}$ in the pore water. In areas of subaqueous discharge geochemical anomalies were detected. Here, the differentiation of trace elements $(\mathrm{Zn}, \mathrm{Ni}, \mathrm{Cd}, \mathrm{Cu}, \mathrm{Pb})$ and their accumulation in the solid phase and pore waters in the surface layer of sediment were observed. The concentrations of trace elements reached toxic levels for water organisms: copper - up to $130 \mathrm{mkg} / \mathrm{l}$; cadmium - $15 \mathrm{mkg} / \mathrm{l}$; lead - $20 \mathrm{mkg} / \mathrm{l}$; nickel - 30 $\mathrm{mkg} / \mathrm{l}$; zinc - $1 \mathrm{mg} / \mathrm{l}$.

Based on the bioassay data, we assume the existence of toxic factor of natural origin, which is related to the accumulation of toxic trace elements in zones of tectonic faults in the central parts of Lake Onego.

New data on the toxicity of sediments in the central parts of Lake Onego are of importance in developing lake monitoring in terms of macrozoobenthos. Heavy metals ( $\mathrm{Zn}, \mathrm{Ni}, \mathrm{Cd}, \mathrm{Cu}, \mathrm{Pb}$ ) which enter the sediment in subaqueous discharge may adversely affect the benthic organisms, namely, to limit their number in the deep area in Lake Onego. This assumption is confirmed by observational data on abundance and biomass of benthic organisms which are the lowest in the deep part of Lake Onego [17].

\section{CONCLUSIONS}

The results of bioassay of sediments show that the most bottom areas of Lake Onego are characterized by non-toxic sediments at present time. The toxic sediments were found in Kondopozhskaya Bay, polluted by wastewater of pulp-and-paper mill, as well as in the Petrozavodskaya Bay and in the Povenets Bay which are anthropogenically affected. The hypothesis on the existence of a toxic factor of natural origin which is related to the accumulation of toxic trace elements in zones of tectonic faults in the central part of Lake Onego is proposed. The data obtained should be taken into account in biomonitoring of Lake Onego.

The study has been financially supported by the Russian Science Foundation (\#14-17-00766).

\section{REFERENCES}

[1] Lake Onego. Atlas / Editor. Ed. N. N. Filatov. Petrozavodsk: Karelian Research Centre, 2010.

[2] N. V. Ilmast. Fish populations of freshwater ecosystems of Karelia in terms of economic development. thesis, Moscow, Moscow State University. 2012.

[3] Water Framework Directive (WFD) 2000/60/EC: Directive 2000/60/EC of the European Parliament and of the Council of 23 October 2000 establishing a framework for Community action in the field of water policy [Online]. Available: http://ec.europa.eu/environment/water/water-framework/

[4] Recommendations R. 52.42.763-2012. Assessment of the state of freshwater ecosystems on a range of chemical and biological indicators. Rosgydromet, Rostov-on-Don. 2012.

[5] Basics of ecogeology, bioindication and biological testing of aquatic ecosystems. SPb .: Publishing House, St. Petersburg. University Press, 2004.

[6] I. Tomilina Ecological and toxicological characterization of sediment of water bodies in Northwest Russia. Borok. 2000.

[7] N. S. Zhmur Method of determining of the toxicity of water and aqueous extracts from soils, sewage, sediments and waste using the parameters of mortality and fertility of Ceriodaphnia. Moscow: Akvaros 2001.

[8] B. A. Flerov and N. S. Zhmur. Bioassay using Ceriodaphnia. Methodological guide for biotesting of water using Ceriodaphnia. RD-118-02-90. Moscow, 1991, pp. 19-28.

[9] I. V. Chalova. Using of bioassay on Ceriodaphnia affinis Lillijeborg in ecotoxicological studies. Physiology and Toxicology of freshwater animals. Rybinsk, 2007, pp. 252268.

[10] N. M. Kalinkina, N. A. Berezina, A. I. Sidorova, N. A. Belkina and A.K. Morozov, "Toxicity Bioassay of Bottom Sediments in Large Water Bodies in Northwestern Russia with the Use of Crustaceans,” Water Resources, Vol. 40. No. 6, pp. 657-666, 2013.

[11] G. Y. Rinkis., H. K. Ramane, and T. A. Kunitskaya. Methods of analysis of soils and plants. Riga: Zinatne, 1987.

[12] Yu. G. Khabarov, "Use of nitric acid for determination of lignosulfonates,” Russian Journal of Applied Chemistry, Vol. 77, No. 5, pp. 858-860, 2004.

[13] E. V. Arinushkina Guidance on chemical analysis of soil. Moscow: Moscow State University, 1961.

[14] E. V. Vanchikov, B. M.,Kondratenok, and V. V. Stalyugin. Quantitative photometric analysis. Syktyvkar. 1999 
[15] AD. Lukashov, "Geodynamics of modern times," in Deep structure and seismicity of the Karelian region and its surroundings. Ed. N. V. Sharov. Petrozavodsk: Karelian Research Centre of Russian Academy of Sciences, 2004, pp. 150-192.

[16] G. S. Borodulina and N.A. Belkina. Study of the geochemical anomalies at the water-sediment boundary in subaqueous groundwater discharge zones in lake Onego. 32nd congress of the international society of limnology. August 4-9, 2013, Budapest. 2013.

[17] T. N. Polyakova, "Macrozoobenthos," in Lake Onego. Atlas. Petrozavodsk: Karelian Research Centre of Russian Academy of Sciences, 2010, pp. 119-121. 